\title{
ASALTAR EL CANON
}

\section{Juan Carlos PUEO}

Universidad de Zaragoza

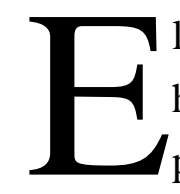
1 clásico es el que permanece, por encima del movimiento diacrónico, de lo intrínsecamente histórico: períodos, corrientes, escuelas e incluso autores, todo lo que desaparece arrastrado por el tiempo. Hubo una época en la que todo eso resultaba accesorio, y la poesía era el terreno en el que se asentaban valores eternos e indiscutibles. Hizo falta que la Modernidad desarrollara una aguda sensibilidad respecto a lo que significaba el paso del tiempo para que la literatura comenzase a exponerse según los principios de una narrativa atenta a su condición de «gran relato», con correlaciones de causa y efecto, actantes motores de éstas e incluso una particular noción de «progreso» a la que apelaron escritores y críticos, convencidos todos ellos de que la literatura era fundamentalmente cambio, reacción contra un pasado destinado a transformarse.

No es extraño, por tanto, que el clásico pasase a ocupar un lugar diferente en el imaginario, bien que en una dialéctica más compleja de lo que podría parecer en un principio, y a la que no es ajena la «angustia de las influencias» descrita por Harold Bloom (1973). La historia de la literatura se ha descrito como una cadena de reacciones contra las viejas formas, representadas por los textos de antaño, en una narración algo simplista, pero eficaz: los escritores, deseosos de formar parte del panteón literario en el que ven elevados a los clásicos, tratan de imponerse a base de «dominio del lenguaje metafórico, originalidad, poder cognitivo, sabiduría y exuberancia en la dicción» (Bloom, 1994: 39). Ello implica cierta pérdida de autoridad del clásico, representante de «lo viejo» aunque sólo sea por la vigencia que su modelo ha mantenido para ser imitado. Aun cuando el clásico siga manteniendo su prestigio como modelo literario, mantiene una posición inestable frente a «lo nuevo», que trataría siempre de comerle terreno, si no de desplazarle.

La moderna inestabilidad del clásico le obligó a desalojar el panteón para mudarse al canon. A diferencia del canon bíblico, prototipo del canon cerrado al que no se le puede añadir ni sustraer ningún texto, el canon literario es un canon abierto en el que la acumulación de textos produce efectos de desplazamiento, desde el momento en que la obra deja de ser actual para convertirse en referente para posteriores generaciones de escritores. Afortunadamente, la historia de la literatura no se reduce a una simple alternancia de autores y obras que manifiestan actitudes de rechazo hacia otros autores y obras 
previos, al tiempo que aceptan otros. Hay más fuerzas en juego, y las reacciones que provocan los textos canónicos son mucho más complejas que un rechazo o una aceptación explícitos ${ }^{1}$. Por esta razón, la inestabilidad del clásico es mucho mayor, hasta el punto de que «las condiciones históricas perfiladas por la “temporalización y la innovación” excluyen por sí mismas la posibilidad de originar y perpetuar un canon real» (Gumbrecht, 1988: 62). Como es bien sabido, la posición del clásico en el canon se establece según niveles jerárquicos, pero, a diferencia del panteón antiguo -donde no había posibilidad de cambio-, esa posición puede variar, desplazándose del margen al centro, o viceversa, o permaneciendo en un discreto rincón del que puede salir en cualquier momento. Las posibles combinaciones en este sentido son inmensas, casi infinitas, pues lo que distingue al canon literario es su variabilidad, su perenne mutabilidad: su proteísmo.

Esta particularidad puede inducir a la tentación de querer acabar con el reinado de los clásicos, de dinamitar el canon de tal manera que sobre sus escombros se construya un canon completamente nuevo, desvinculado del prestigio que proporciona la pátina del tiempo: una operación que alcanzó su mejor expresión durante las vanguardias históricas, con un vigor nada desdeñable, ya que no se trataba únicamente de ofrecer una alternativa al canon tradicional, sino que había también un saludable deseo de épater le bourgeois, de golpearle en sus convicciones culturales de respetabilidad, tradición y orden. La presentación en sociedad de un joven poeta ultraísta, César González-Ruano, pasaba no sólo por realizar gestos epatantes, sino por manifestar una posición furiosamente anticanónica, que dejase bien clara su adscripción a la nueva estética vanguardista, tal como relata en sus memorias Mi medio siglo se confiesa a medias (1950):

Y llegó el día de la conferencia. Yo quería aprovechar aquella ocasión para hacer algo sonado. Había que salir, que romper por algún sitio. Hasta el día anterior no decidí la cosa. Fui al Ateneo como el anarquista que lleva su bomba. Algo notaron en mí algunos amigos.

- ¿Qué es eso? ¿Te has teñido el pelo?

-Sí; he decidido ser rubio una temporada.

Llevaba yo el pelo muy largo. Acababa de darme agua oxigenada y me había puesto un chaleco amarillo y metálico de mujer. Subí a la tribuna sin tener nada aprendido, pero dispuesto a «armar la gorda» y a meterme con Cervantes, que me parecía que podía ser lo que más irritara. Me presentó Ramón Ledesma Miranda, que no sabía del todo lo que iba a hacer. Cuando terminó me levanté yo medio lívido a tirar mi bomba. No puedo precisar cómo empezó la cosa. Aproximadamente yo dije:

-Señoras y señores: Por mí pueden ustedes levantarse e ir a decir vuestras tonterías a otro sitio. Yo no tengo ningún agradecimiento a que estéis oyéndome, ni voy a decir nada de que éste sea un público selecto ni mucho menos.

Hubo una como estupefacción general, pero no se movió nadie. Entonces yo continué:

-Estoy harto de oír aquí a una serie de memos hablar del idioma de Cervantes. Ese Cervantes parece que era un manco, cosa que se confirma, porque el Quijote está escrito con los pies...

No se pudo seguir. Ni yo podría describir aquí el escándalo que se organizó. Varios ateneístas se lanzaron a pegarme y otros, amigos, formaron como una barrera de defensa.

- ¡Señores! ¡Señores! -gritó el joven Pérez-Doménech, que era secretario creo de la Junta-. ¡Ha sido sorprendida la buena fe del Ateneo! ¡Calma, señores!

Me insultaban. Yo insultaba, puesto en jarras. Un ordenanza trajo a la pareja de guardias de orden público que solían estar de servicio por la calle del Prado, y a empujones salí de allí entre una pita descomunal.

\footnotetext{
${ }^{1}$ No voy a detenerme en esta cuestión. El lector interesado en las posibles modalidades de reacción ante los textos literarios puede dirigirse a dos libros clásicos de teoría literaria: el ya aludido La angustia de las influencias de Harold Bloom (Bloom, 1973) y Palimpsestos: la literatura en segundo grado, de Gerard Genette (Genette, 1982). Y seguir adelante.
} 
La «conferencia», con insultos, guardias y todo, debió de durar ocho o diez minutos (González-Ruano, 1950: 110).

Es posible que la memoria de González-Ruano le traicionase algo en este relato, pues la crónica que publicó al día siguiente La Correspondencia de España hace notar que el aspirante a escritor leyó algunos poemas después de su alegato anti-cervantista, ante un auditorio que, con todo, no dejó de manifestar su hostilidad ${ }^{2}$. Aun así, lo más relevante de la anécdota sigue siendo el gesto iconoclasta, que describe perfectamente la mentalidad del joven literato dispuesto a destrozar el canon por la vía rápida: un gesto que, como reconoce el propio escritor, no tenía otra intención que la de «hacer algo sonado», «romper por algún sitio» $\mathrm{y}$, de esta manera, hacerse un hueco en el mundo literario. Evidentemente, la posición de Cervantes en el canon no sufrió la menor modificación tras el ataque de González-Ruano, quien, tras lograr su objetivo de situarse en la literatura y el periodismo, acabaría por dedicarle los mayores elogios, demostrando que la iconoclastia no suele llegar muy lejos cuando se mantiene como postura extrema. Por esta razón, la vanguardia no tardó en adoptar una posición más ponderada, como lo demuestra el ejemplo de Guillermo de Torre en el «Fronstipicio» de sus Literaturas europeas de vanguardia (1925):

Que tan fervorosa devoción al presente implique, en cierto modo, un desdén negativo del pasado es cosa -como deduciréis- que no me desconsuela. Mas, como sin embargo no creo ya oportuno repetir los fáciles latiguillos marinettianos de execración pasadista, ni me asocio a la liga vetustófoba para la incineración de museos y bibliotecas, voy a delimitar sumariamente mi actitud, que tampoco querría llevar hasta el extremo opuesto: la modernolatría. El pasado artístico, abstractamente, no me interesa como tal, en su fría reducción museal, en su yacente esterilidad estatuaria. Me interesa el pasado en función del futuro, y mejor aun del presente. En sus potencias no marchitas. Como substratum y base para garantizar la solidez del terreno ideológico sobre el que nos asentamos. Del pretérito remoto su virtual pervivencia, visible, no en sus ficticias evocaciones o continuaciones sino en su eco vivo, en su prolongación virtual. De ahí que los clásicos, ciertos clásicos, sólo nos interesen por sus virtudes asimilables, adherentes al espíritu moderno -según tendrá ocasión de comprobarse en algún capítulo de este libro-: En lo que muestran de afán con nuestra sensibilidad actual: En su fermento inagotable de posibilidades deveniristas. He ahí, a mi juicio, el único punto de vista admisible. Lo demás... es superstición y arqueología... (De Torre, 1925: 47).

La aceptación de «ciertos clásicos» implica una asunción de la maleabilidad del canon, al mismo tiempo que demuestra la imposibilidad de destruirlo. No es ninguna casualidad que la celebración, dos años después, por parte de un grupo de jóvenes poetas, del tricentenario de la muerte de Góngora se convirtiese para la historia de la literatura en el acto fundacional de una estética que aceptaba por un lado los modos de la vanguardia más radical y, por otro, buscaba el retorno a las fuentes de una poesía pura que podía hallarse tanto en la poesía popular como en Manrique, Garcilaso o el mismo Góngora, una vez despojados de la ganga erudita y pedante con que los solía presentar la crítica de la época.

A pesar de todo, es difícil renunciar a la tentación iconoclasta, que no ha dejado de estar presente en movimientos contraculturales de distinto signo, al menos hasta los albores de la Postmodernidad, e incluso hasta nuestros propios días. Más allá del gesto promocional, el ataque al canon puede esconder una reflexión de mayor calado en torno a determinados aspectos del mismo, sus injusticias o sus debilidades. Uno de los textos más reveladores lo ofrece otro escritor de filiación vanguardista,

\footnotetext{
${ }^{2}$ Anónimo, «La conferencia de ayer», La Correspondencia de España (3-2-1922), p. 8.
} 
Giovanni Papini, en el marco de Gog (1931), su particular miscelánea -es difícil asignar a este peculiar libro, y su continuación, El libro negro (1951), a un género concreto-, que da comienzo, tras una introducción en la que el autor se libera de toda responsabilidad, adjudicando el discurso al personaje protagonista, con un texto que lleva el título de «Las obras maestras de la literatura»:

Huestes de hombres, llamados héroes, que se despanzurraban durante diez años seguidos bajo las murallas de una pequeña ciudad, por culpa de una vieja seducida; el viaje de un vivo en el embudo de los muertos como pretexto para hablar mal de los muertos y de los vivos; un loco hético y un loco gordo que van por el mundo en busca de palizas; un guerrero que pierde la razón por una mujer y se divierte en desbarbar las encinas de las selvas; un villano cuyo padre ha sido asesinado y que, para vengarle, hace morir a una muchacha que le ama y a otros variados personajes; un diablo cojo que levanta los tejados de todas las casas para exhibir sus vergüenzas; las aventuras de un hombre de mediana estatura que hace el gigante entre los pigmeos y el enano entre los gigantes, siempre de un modo inoportuno y ridículo; la odisea de un idiota que a través de una serie de bufas desventuras sostiene que este mundo es el mejor de los mundos posibles; las peripecias de un profesor demoníaco servido por un demonio profesional; la aburrida historia de una adúltera provinciana que se fastidia y, al fin, se envenena; las salidas locuaces e incomprensibles de un profeta acompañado de un águila y una serpiente; un joven pobre y febril que asesina a una vieja, y luego, imbécil, no sabe siquiera aprovecharse de la coartada y acaba cayendo en manos de la Policía (Papini, 1931: 16).

El fragmento ha de leerse desde la distancia irónica que proporciona saber que Papini no fue jamás, ni siquiera en sus más exaltados escritos futuristas, un iconoclasta a la manera de Marinetti: «Para Papini el rechazo a la literatura y el arte del pasado no consistirá tanto en destruirlos o negarlos, sino sólo en no sobrevalorarlos en demasía, "in maniera pazzesca", como hace en Italia "la turba innumerevole degli sciocchi”»(Peña, 2007: 22). Su apasionada biografía de Dante, Dante vivo (1933), aparecería tan sólo dos años después de Gog, sin que hubiera en ella el menor rastro de la acerba crítica con que se refiere su obra en el texto citado. El alegato contra el canon pertenece, como ya se ha señalado, a otra voz, la del protagonista del libro, el excéntrico multimillonario creado según el prototipo del self-made man norteamericano y al que se describe diciendo que «parecía que estuviesen unidos en él Asmodeo, con su agudeza cínica, y Calibán, con su ciega torpeza de bruto» (Papini, 1931: 10). Son su torpeza y su brutalidad, combinadas con su inteligencia innata, las que llevan a Gog a emitir esta serie de juicios negativos contra los grandes clásicos de la literatura, después de haberse propuesto conocerlos directamente.

Gog, que nació pobre y dedicó buena parte de su vida a enriquecerse, es para Papini «una especie de símbolo de la falsa y bestial -para mí- civilización cosmopolita, y lo presento a los lectores de hoy con la misma intención con que los espartanos mostraban a sus hijos un ilota completamente borracho» (Papini, 1931: 12). Materialista, pragmático y amoral, puede permitirse el lujo de afrontar la lectura de las obras canónicas con la mayor inocencia, destacando lo absurdo de sus contenidos cuando los analiza desde su mentalidad anti-humanista, atenta únicamente al poder que confiere el dinero y, por consiguiente, al culto narcisista del yo, totalmente desvinculado del resto de la humanidad. En este sentido, la crítica que lanza Gog contra las obras maestras de la literatura, fruto de su incapacidad de disfrutarlas, sería una caricatura de la incapacidad del hombre moderno para reconocerse en estas obras, que ya no le dicen nada porque entiende que no hablan de él, lo cual no puede provocarle otra cosa que desinterés. No en vano, Gog acaba confesando que tras la decepción sufrida por su choque 
contra las obras del canon, la lectura de «algunos escritores jóvenes» le resultó mucho más gratificante, al encontrar en ella, «entre muchas cosas turbias, un alimento más adecuado a mis gustos» (Papini, 1931: 17), esto es, por ser capaz de identificarse con lo que estos jóvenes planteaban desde la más radical contemporaneidad.

Pero aun cuando pueda decirse que lo que animaba a Papini era un propósito satírico contra el materialismo narcisista de una sociedad incapaz de atender a otros valores que no fueran la más acendrada onfaloscopia, su texto puede leerse desde otros niveles, pues la ironía no debe tomarse nunca en vano. Independientemente del valor que diera Papini a las obras descritas en el párrafo citado, lo que se desprende de éste es la posibilidad de una lectura que se enfrenta a todas las que puedan hacerse desde el respeto al canon. Es posible que un párrafo de estas características indigne todavía a algún lector, pero también existen lectores que, sin dejar de reconocer el valor de las obras comentadas, disfrute de la descripción que les dedica Gog. Al igual que ocurre con numerosas parodias, en las que el disfrute de las mismas puede coexistir con el disfrute de las obras parodiadas, el ataque al canon de Gog coloca a los clásicos en otro nivel, completamente diferente, un nivel del que se ha excluido la solemnidad con que se ha mirado y se ha tratado siempre al canon, relativizando su interpretación por medio del humor. Más allá del alegato anti-materialista, queda la certeza de que toda interpretación es posible, desde la que exalta a la obra como insigne monumento de cultura hasta la que la rebaja a desatinada acumulación de necedades, dependiendo las más de las veces de la ironía y el humor con que se lea.

Difícilmente podrá hallarse mejor ejemplo de hasta dónde llega el proteísmo del canon moderno, desde el momento en que la posibilidad de cada obra de ser intepretada de forma diferente implica efectos de desplazamiento en su interior. Es preciso recordar que para la hermenéutica clásica no había tal proteísmo, pues los sentidos también tenían una jerarquía -del sentido literal al sentido místico-, y ésta no modificaba la posición de los textos dentro del panteón: la Biblia siempre estaría en el centro, por más punta que se les pudiera sacar a Homero, a Virgilio o a Séneca; y éstos siempre estarían más cerca del centro que los autores posteriores, aun cuando Dante, Petrarca o Boccaccio pudieran convertirse en modelos más productivos para la literatura moderna. La aparición del canon sólo pudo producirse cuando esta jerarquía empezó a tambalearse y los tres autores del Trecento citados, además de Ariosto, Cervantes, Shakespeare e incluso Ossian, comenzaron a generar interpretaciones que les ponían al mismo nivel que los autores antiguos. Esto es, cuando la poética abandonó su carácter preceptivo, propiciando la dispersión del sentido en múltiples direcciones. Ya lo señaló en su momento José María Pozuelo Yvancos:

No es la supervivencia del comentario lo que permite la canonicidad sino la supervivencia del objeto a comentarios cambiantes y movedizos. La continuidad de atención e interpretación es el criterio básico que permite la canonicidad de un texto y la propia diversidad de sus interpretaciones permite la continuidad de la actividad interpretativa, de modo que la variabilidad relativa de su sentido, aunque aparentemente pueda pensarse anticanónica, es la que asegura un orden acumulativo, al que llamamos tradición, que permite transformar el objeto sin destruirlo (Pozuelo Yvancos, 1995: 13). 
Es una transformación que no afecta únicamente al autor u obra canónicos, sino también a su posición en el canon, que puede ir del margen al centro, de lo sublime a lo despreciable o indigno de atención, y viceversa. El caso expuesto aquí es un caso extremo: al igual que ocurrió con la conferencia de González-Ruano, las invectivas de Gog no lograron en su momento apartar a las obras comentadas del canon, o situarlas en el margen, pues tampoco era ése su objetivo. Sin embargo, tuvieron el poder de desplazarlas, por un momento, a un espacio completamente diferente del que casi siempre han ocupado, desplazamiento que sólo fue posible gracias a la dimensión hiperbólica que otorga el tono humorístico. El texto de Papini demuestra que toda obra puede ocupar, aunque sea de forma momentánea, posiciones muy diferentes dentro del canon. Cada una de las interpretaciones que suscita el autor o la obra la coloca en una posición específica, similar las más de las veces, pero nunca definitiva, pues la obra se halla siempre en movimiento, en tránsito ${ }^{3}$, de una posición en el canon a otra.

Los desplazamientos dentro del canon pueden tener fortuna-recuérdense las reivindicaciones de Shakespeare, Cervantes y Rabelais realizadas por los escritores románticos, o la recuperación de Góngora convertida en signo de identidad de los poetas del 27-, dándose el caso de que un autor pase de una posición secundaria o marginal a otra más cercana al centro. Más efectividad que los gestos puramente iconoclastas suele tener el paso del tiempo, que relega a autores que fueron centrales a posiciones totalmente marginales. No obstante, el paso de una posición a otra no es nunca definitivo, y la obra de un autor seguirá moviéndose en cualquier dirección. José María Valverde, que solía jugar con el canon tomándoselo irónicamente, hasta el punto de describir al Quijote como una novela inglesa del XVIII o a Diderot como un prerromántico alemán, no tenía ningún escrúpulo en presentar a Góngora, dentro de su idea de la literatura barroca, como «un extraordinario "poeta menor", antecesor de las aventuras estéticas de nuestro siglo, en exploración de las fronteras de la poesía» (Valverde, 1969: 240). Sabemos que este desplazamiento de Góngora al espacio de los poetas menores, en el que, por cierto, ya había estado, no ha tenido ningún efecto dentro del canon consensuado por críticos, profesores, etc. Pero en el texto de Valverde - al igual que en otros textos en los que habla de esta cuestión, como El barroco: una visión de conjunto (1980) o Historia de la literatura universal (1985)-, tanto Góngora como Lope aparecen desplazados, dejando un hueco que no tarda en ser ocupado por el conde de Villamediana, el conde de Salinas y Gabriel Bocángel, promocionados por Valverde al rango de máximos exponentes, junto a Quevedo, de la poesía barroca hispánica. El canon queda, así, ligeramente conmovido, aunque sólo por un breve momento, pues la institución literaria no ha aceptado esta propuesta de variación, prefiriendo mantener a Góngora como el poeta prototípicamente barroco.

Establecer rankings definitivos dentro del canon, o pretender situar a un autor en su centro, de forma inconmovible, como quería hacer Bloom con Shakesperare, es una empresa vana: el canon es

\footnotetext{
${ }^{3}$ «Teoría, pues, como tránsito hacia alguna respuesta que la iterancia remite reiteradamente a otro lugar, iterancia sin punto de partida ni lugar de llegada, sin origen ni meta, tránsito de la teoría, tránsito de la mirada, tránsito de la procesión: tránsito del tránsito: tránsito» (Blesa, 2004: 91).
} 
como el río de Heráclito, nunca es el mismo, aunque el paisaje pueda hacer que parezca siempre igual. Se ha de tener en cuenta que el autor o la obra canónicos ocupan su puesto en relación a la posición que ocupan los demás autores y obras canónicos, todos ellos desplazándose de forma continua, sin posibilidad de detenerse en ningún momento. El simple acto de poner el foco en un autor concreto, destacando su valor estético o su originalidad más allá de los modelos que puedan haberle inspirado, supone un cambio en el canon, pues la pretendida estabilidad de los autores que ya estaban ahí antes se ve conmovida en ese mismo instante, si bien lo más habitual es que se trate de un efecto pasajero: lo cierto es que las reivindicaciones de autores postergados como Malón de Chaide, Álvarez de Cienfuegos o Núñez de Arce no han logrado sacarlos del olvido. No obstante, el gesto reivindicador, al igual que el gesto iconoclasta, supone un cambio, y los autores citados, como muchos otros, experimentan un brillo -efímero, pero no despreciable- que eclipsa, también de forma momentánea, a aquellos autores que se sitúan habitualmente en el centro. Lo cual, como ocurre con el ejemplo de Valverde, no deja de tener un saludable efecto de ventilación en el canon.

No se puede evitar que cada intervención crítica sostenga, implícita o explícitamente, un juicio de valor que altere de alguna manera el juego de fuerzas que estructura el siempre proteico canon. No debemos olvidar que «all value is radically contingent, being neither a fixed attribute, an inherent quality, or an objective property of things but, rather, an effect of multiple, continously changing, and continously interacting variables or, to put it in another way, the product of the dynamics of a system» (Smith, 1988: 30). Esto no es sólo aplicable a las obras que conforman el canon, sino a la propia actividad crítica que lo sostiene: si el valor de la obra es contingente, el método encargado de sacarlo a la luz no lo será menos. Así pues, no habrá manera de fijar el canon a partir de categorías universales. La polémica sobre la naturaleza -estética o política- del canon enfrenta a dos posturas a las que, en realidad, une su voluntad de poner puertas al campo. La única forma de caracterizar al canon literario es atender a su proteísmo: el canon no puede fijarse, pues se trata de un espacio cuyos integrantes están siempre en movimiento, desplazados las más de las veces por los movimientos de los demás.

No obstante, que los resultados de este movimiento perpetuo sean más o menos efímeros, más o menos perdurables, eso ya es otro cantar. La Ilíada y la Odisea siguen siendo referencia indiscutible en toda historia de la literatura occidental que se precie, a pesar de todos los ataques que, desde distintas posiciones, ha recibido Homero a lo largo de más de veinte siglos. Lo mismo que Cervantes, Shakespeare o Goethe. Al fin y al cabo, no podemos olvidar que existe una institución literaria que funciona por consensos, estableciendo jerarquías autorizadas entre los indiscutibles, los consagrados, los secundarios y los marginales, y aceptando también determinados desplazamientos hacia el grupo de los olvidados o el de los recuperados. Construyendo, en definitiva, un imaginario del que es difícil escapar. El lector de cierto nivel cultural que se enfrenta al tex to de Papini citado arriba puede encontrar placer - más o menos culpable, depende del caso- al advertir la ácida caracterización que dedica Gog a cada una de las obras maestras de la literatura, y hasta es posible que esté de acuerdo con alguna de sus apreciaciones. Sin embargo, este placer se combina, no sin ironía, con el placer del reconocimiento: obsérvese que Papini no cita a las obras por su título, sino que incita al lector a que sea él quien las 
identifique, como si se tratase de un juego, a partir de la sarcástica perspectiva con que las describe. Y el hecho de que todavía seamos capaces de hacerlo es prueba suficiente de que el canon tradicional resiste.

\section{Bibliografía citada}

BLESA, Túa (2004): Tránsitos: escritos sobre poesía. Valencia, Tirant lo Blanch.

BLOOM, Harold (1973): La angustia de las influencias. Trad. Francisco Rivera. Caracas, Monte Ávila, $2^{\mathrm{a}}$ ed., 1991.

- (1994): El canon occidental. Trad. Damián Alou. Barcelona, Anagrama, 1995.

Cervera, Vicente - Hernández, M. ${ }^{a}$ Belén - Adsuar, M. ${ }^{a}$ Dolores, eds. (2007): Giovanni Papini. El prisionero de sí mismo. Murcia, Universidad de Murcia.

DE TORRE, Guillermo (1925): Literaturas europeas de vanguardia. Sevilla, Renacimiento, 2001.

GenetTE, Gérard (1982): Palimpsestos. La literatura en segundo grado. Trad. Celia Fernández Prieto. Madrid, Taurus, 1989.

GonZÁlez-RuAnO, César (1950): Mi medio siglo se confiesa a medias. Sevilla, Renacimiento, 2004.

GuMBrecht, Hans Ulrich (1988): ““Cual Fénix de las cenizas” o del canon a lo clásico», en SuLLÀ, comp. (1998), pp. 61-90.

PAPINI, Giovanni (1931): Gog. Trad. Mario Verdaguer. Barcelona, Plaza \& Janés, 1982.

PEÑA, Victoriano (2007): «Giovanni Papini, futurista sui generis», en CERVERA-HernándeZADSUAR, eds. (2007), pp. 17-43.

Pozuelo Yvancos, José María (1995): El canon en la teoría literaria contemporánea. Valencia, Episteme.

SMITH, Barbara Herrstein (1988): Contingencies of Value: Alternative Perspectives for Critical Theory. Cambridge (Mass.), Harvard University Press.

Sullà, Enric, comp. (1998): El canon literario. Madrid, Arco.

VALVERDE, José María (1969): Breve historia de la literatura española, en Obras completas. Madrid, Trotta, 1999, vol. III, pp. 169-332. 